\title{
CESIÓN DE LA PROPIEDAD EN EL SEÑORÍO DE ELCHE: LOS ARRENDAMIENTOS RÚSTICOS ILICITANOS A PRINCIPIOS DEL SIGLO XVIII (1715-1730)
}

\section{Por María del Carmen IRLES VICENTE}

El estudio de la documentación notarial es harto importante para el conocimiento y comprensión de cualquier época que cuente con esta fuente de información, por cuanto a traves de las actas notariales queda reflejada la realidad de una determinada área en un período cronológico concreto: su movimiento económico, las relaciones económicas y sociales entre los individuos y entre los grupso, aspectos culturales, etc. ${ }^{(1)}$.

Así, y en nuestro caso, al intentar seguir el movimiento de cesión de la tierra en el término ilicitano a principios del XVIII, hemos elegido como fuente básica a partir de la cual realizar dicho estudio las escrituras de arrendamiento redactadas por los quince escribanos que desempeñaban dicha labor en Elche en el período 1715-1730. El análisis de esas actas notariales ha permitido perfilar qué grupo social empleaba con mayor frecuencia el sistema de arriendo, si predominaba el arriendo con pago en metálico o en especie, duración del mismo, condiciones pactadas entre arrendador y arrendatario para mantener o mejorar el estado de las tierras objeto de arriendo, la alternancia de cultivos, utensilios de labor... ${ }^{(2)}$

Una limitación impuesta por las escrituras ilicitanas es no poder perfilar con absoluta claridad la pertenencia de los individuos que participan en el acto jurídico a un determinado grupo dentro de cada estamento, ya que dichas escrituras no indican, por lo general, la profesión de arrendador ni arrendatario.

Para estudiar el movimiento de cesión de tierras en arriendo dividiremos el trabajo en dos partes; en la primera se analizarán, de modo general, las conclusiones extraídas para el total de escrituras $-441-$, en tanto que posteriormente se pasará al estudio de un tipo de cesión, en concreto los arriendos de huertos de palmeras, los cuales tanto por el interés que despiertan entre los arrendadores ${ }^{(3)}$, por el precio que alcanzan, como por las especiales características dentro del término ilicitano merecen se les dedique un apartado propio. 


\section{ARRENDAMIENTOS RÚSTICOS. CARACTERÍSTICAS GENERALES}

En el período 1715-1730 se contabilizan en los protocolos ilicitanos 441 cesiones de tierras en arriendo, tierras que pertenecen a miembros de los tres estamentos clásicos del Antiguo Régimen en porcentajes variables (cuadro I).

\section{CUADRO I}

\section{CESIÓN DE LA TIERRA EN ARRENDAMIENTO (POR ESTAMENTOS)}

\begin{tabular}{|c|c|c|}
\hline ESTAMENTo & N. ${ }^{\circ}$ DE CASOS & PORCENTAJE \\
\hline Nobleza titulada ............ & 10 & 2,26 \\
Pequeña nobleza (4) ........ & 204 & 46,25 \\
Instituciones eclesiásticas . & 81 & 18,36 \\
Patrimonio eclesiástico..... & 20 & 4,53 \\
Plebeyos ....................... & 126 & 28,57 \\
\hline TOTAL ...................... & 441 & 100 \\
\hline
\end{tabular}

Fuente: A. M. E. Protocolos (elaboración propia)

Como vemos, los propietarios-arrendadores de tierras pertenecen mayoritariamente a las capas altas de la sociedad ilicitana de principios del XVIII -aparecen con frecuencia apellidos ilustres descendientes de catalanes y aragoneses asentados en Elche tras su conquista a los musulmanes en el siglo XIII; así Malla, Miralles, Ortiz, Perpiñán, Ruiz...-, aunque sin menospreciar la presencia (superior al $25 \%$ ) de arrendadores del estado llano.

Los arrendatarios, sin embargo, forman parte mayoritariamente del estamento plebeyo, siendo escasas las ocasiones en que un noble o eclesiástico se ve tentado a tomar tierras en arriendo ${ }^{(5)}$.

En un $25 \%$ de contratos aparece la figura del fiador o persona que garantizaba el pago del precio estipulado en caso de que el arrendatario se viera imposibilitado a efectuarlo por sí mismo. Sin embargo, y en contra de lo que sucede en los contratos de arrendamiento suscritos en la ciudad de Alicante, en las escrituras ilicitanas no figura la relación de bienes de estos avalistas ${ }^{(6)}$.

La duración se fija, por lo general, en un determinado número de años a cumplir obligatoriamente, aunque también, en algunos casos, se establece la posibilidad de ampliar o reducir el período de aprovechamiento en uno o dos años - son los llamados años precisos y voluntarios.

La duración de los arriendos rústicos analizados suele oscilar bastante, encontrando desde cesiones por un solo año hasta otras que llegan a los 22 . No obstante, lo más frecuente suelen ser cesiones por 6,4 y 8 años ${ }^{(7)}$.

Aunque el arrendamiento puede comenzar en cualquier momento del año, 
la costumbre y el ritmo de las cosechas hace que predominen unas determinadas fechas para cada tipo de cultivo. Así:

- la cosecha de aceituna suele recogerse en noviembre-diciembre, por lo que el arrendamiento de olivar empieza a contar desde Navidad o primero de año.

-el arrendamiento de las tierras blancas de secano suele comenzar por San Miguel debido a que éste es el momento en que se siembra el grano - principal aprovechamiento de estas tierras - cuya cosecha se recogerá a comienzos del verano.

- las haciendas con distintos arovechamientos (higueras, viña...) suelen cederse a partir de San Miguel - momento en que las uvas e higos han sido ya recolectados-o principio de año.

\section{- los medianos desde San Miguel o San Juan.}

El precio a satisfacer por el disfrute temporal de unas tierras viene expresado en metálico en la totalidad de los arrendamientos rústicos del término ilicitano -excepción, por supuesto, de la aparcería ${ }^{(8)}$ _, encontrando, sin embargo, que algunos arrendadores con propiedades en la huerta de Orihuela, y cuyas escrituras se pasan ante escribanos ilicitanos, solicitan el pago en especie ${ }^{(9)}$.

Muchas veces, cuando la cantidad a abonar se fija en metálico, se exige, además, la entrega de cierto número de gallinas o una cantidad de frutos (dátiles, albaricoques, peras...). Se trata de un aporte adicional de carácter simbólico, cuya significación económica es mínima, y que venía a suponer el reconocimiento, por parte del arrendatario, de a quien pertenecía en última instancia la propiedad.

El pago del precio estipulado en los contratos se satisfacía, por lo general, con carácter anual, ya sea en una sola fecha o dividido en varios plazos.

Cuando el precio se satisface en un único plazo éste suele coincidir con la festividad de San Miguel, Navidad o San Juan; siendo también muy numerosos los pagos el último día del año. Entre aquellos arrendamientos que dividen sus vencimientos en dos pagas sobresalen las fechas elegidas en San Juan-Navidad y San Miguel-Navidad. También en algunas ocasiones se establece el pago repartido en tres plazos, siendo entonces mayoritaria la elección de estas tres fechas: San Juan-San Miguel-Navidad. Unas mismas fechas con múltiples combinaciones debido a la importancia de éstas por lo que al año agrícola se refiere (recogida de las diversas cosechas - sembrados, uva, olivas...-).

También algunas veces se señala la necesidad de adelantar una determinada cantidad en el momento de formalizar la escritura.

Relacionado con el pago del precio en que se cedieron las tierras hay un pacto que impide al arrendatario «pedir rebaja ni refacción alguna por ningún caso fortuito ya sea de fuego, robo, aguas, piedra, langostas, niebla, granizo, guerras, peste, falta de cabalgaduras, ni otras plagas ni casos fortuitos, ni causas mayores o menores o iguales a las expresadas, porque este arrendamiento lo hago a toda fortuna y riesgo del... arrendador (arrendatario) ${ }^{(10)}$. Aparece en una tercera parte de los arriendos rústicos revisados, sin que suponga una característica exclusiva del Antiguo Régimen ${ }^{(11)}$. 
Además de indicar quiénes son las partes contratantes, la ubicación y características de la tierras arrendadas (cultivo al que se dedican, si llevan adjuntas alguna cantidad de agua para su riego...), duración del arriendo, precio y plazos de pago, los contrato de arrendamiento incluyen un apartado en el que se establece cuál habrá de ser la actuación del arrendatario sobre las tierras tomadas en arriendo (labores a realizar, estructuras a mantener, cuidados a prodigar, etc.), así como la del propietario de las mismas respecto a aquél. Las condiciones pactadas entre ambas partes se pueden agrupar, en base a su afinidad temática, en:

a) Forma o modo de cultivo. El pacto por excelencia en todos los contratos de arrendamientos rústicos hace referencia a la necesidad, por parte del arrendatario, de «cultivar las tierras a uso y costumbre de buen labrador». Con esta cláusula el propietario intentaba controlar la actuación del arrendatario sobre las tierras arrendadas para evitar el deterioro de éstas. Además, en muchos casos se matiza que de no cumplir con la condición arriba expresada, el propietario podría quitarle la finca, perdiendo aquél todo lo que hubiese trabajado y debiendo pagar los deterioros que se encontrasen.

Las labores a realizar varían en función del cultivo establecido, siendo las más características el arado de campos, la poda de árboles, el estercolado y riego de las tierras, etc.

También frecuentemente los contratos recogen una cláusula por la que se prohíbe a los arrendatarios hacer leña, cortar o arrancar cualquier árbol sin expresa licencia por escrito del propietario, debiendo satisfacer fuertes multas de incumplir dicho pacto.

b) Mantenimiento y mejora de la infraestructura e instrumental de la hacien$d a$. La preocupación de los propietarios afecta tanto a las tierras arrendadas como a los edificios que se hallen en las mismas o a los aperos de labranza que se cedan con ellas. Así, muchos arrendatarios habrán de limpiar las vertientes ${ }^{(12)}$ de la hacienda, las acequias e incluso ocuparse de recomponer la finca cuando ésta ha sufrido deterioros por lluvias, avenidas de agua...

También, y cuando en las tierras arrendadas existen casas, almazaras, norias, etc, los arrendatarios deben mantener el buen estado de los inmuebles, ya sea arreglando por su cuenta los desperfectos que se produzcan o colaborando con el popietario en su mejora ${ }^{(13)}$.

Entre el instrumental cedido a los arrendatarios figuran azadas, legones, otros aperos, así como botas para guardar el vino tras la vendimia.

c) Muchos contratos contienen una serie de cláusulas referentes a los animales que se hallan en la hacienda. Estas suelen ser de dos tipos:

- unas van dirigidas a evitar que gallinas u otros animales, libres por los campos, puedan afectar a las cosechas comiéndoselas o deteriorándolas;

-otras a propiciar el cuidado y/o reproducción de los animales existentes en la hacienda por parte del arrendatario.

d) Prestaciones adicionales en especie. Como se ha indicado más arriba -al tratar del pago del arrendamiento-, en ocasiones los arrendadores solicitan de- 
gustar los frutos cosechados en sus tierras, para lo cual han de entregárseles una cierta cantidad de los mismos (higos, almendras, granadas, aceitunas...) o bien aves (gallinas, palomas) en reconocimiento de propiedad.

e) Además de los indicados, existen en las cláusulas de los contratos de arrendamiento otros pactos que hacen referencia al pago o no de las mejoras introducidas por los arrendatarios en las tierras; al empleo del estiércol producido en la hacienda en el abonado de la misma; a las reservas, por parte del propietario, de tierras, árboles o edificios que se hallen dentro de los límites de lo arrendado; al aprovechamiento de los pozos de agua dulce -cuando éstos existen en las fincas-; a la posibilidad de venta de tierras cedidas en arriendo; cambio de las mismas por otras de iguales características; renovación de contratos; subarrendamientos, etc.

\section{CULTIVOS}

Las tierras arrendadas registran los diferentes aprovechamientos que se dan en el agro ilicitano a principios del XVIII: olivar, viña, cereales - sobre todo cebada - , higueras, algarrobos, almendros, granados, perales, albaricoqueros, palmeras, alfalfa, barrilla, legumbres y hortalizas.

Aunque los cultivos asentados en el término eran, según vemos, numerosos, los tres pilares sobre los que se asentaba la agricultura ilicitana durante el XVIII eran el olivo, la cebada y la barrilla ${ }^{(14)}$, cultivos todos ellos que se destinaban, en gran parte, a la exportación.

En el mapa de la página siguiente se registran los diferentes cultivos del término ilicitano con el reparto geográfico que constatamos en base a las escrituras de arrendamiento. A la vista de dicho mapa podemos observar cómo casi en todas las partidas aparecen los mismos cultivos ${ }^{(15)}$; lo único que cambiaría serían las proporciones ocupadas por cada uno, pero que en nuestro caso no es significativo, ya que muchas veces es una misma parcela la que aparece arrendada en varias ocasiones a lo largo del período y cuando no, lo que tenemos son datos parciales de las tierras de una partida - aquellas que se ceden en arrendamiento- ${ }^{(16)}$.

Concluiremos este apartado con la imagen-resumen que Cavanilles dejó del reparto de cultivos en franjas alrededor del núcleo urbano: en primer lugar, y circundando la villa, huertos de palmeras; cercando a éstos una faja más ancha donde se cultivaba trigo, barrilla, alfalfa, etc.; aún otro círculo más amplio rodea estas tierras, son los olivares, y éstos a su vez, enmarcados por tierras, generalmente de secano, dedicadas a cereales y árboles como higueras o algarrobos ${ }^{(17)}$. 


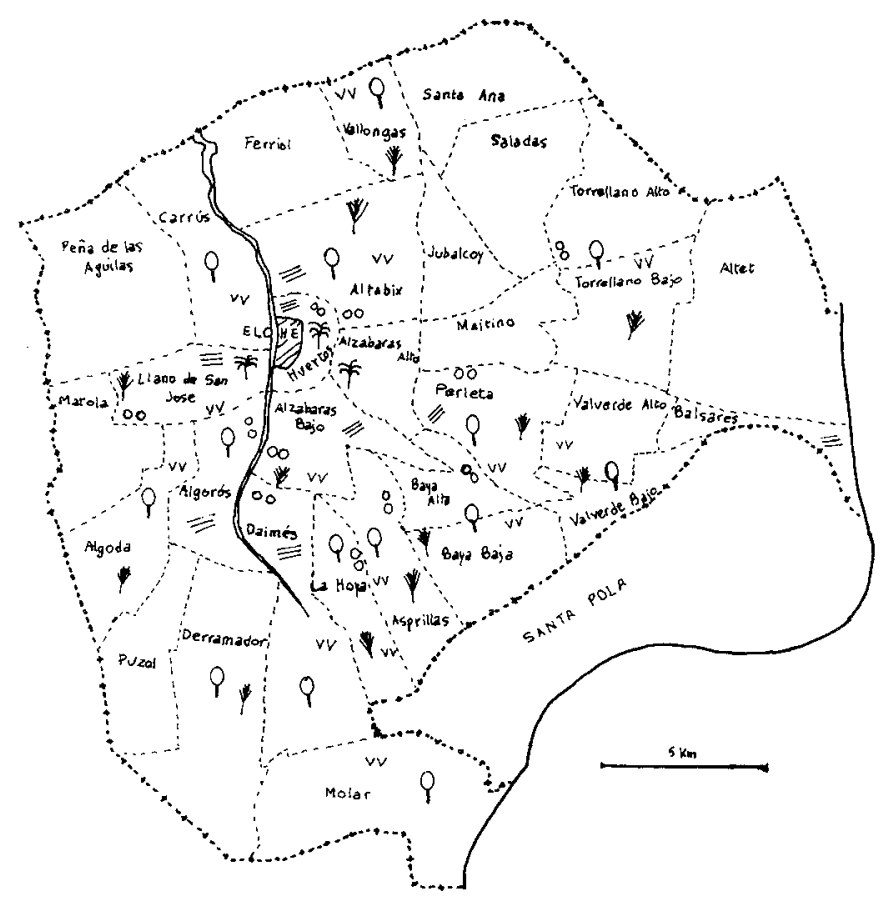

CULTIVOS:

$\Psi$ cereales

$\checkmark v$ viña

oo olivo

₹ palmeras

$\equiv$ medianos

9 árboles (higueras, algarrobos...) 


\section{ARRIENDO DE HUERTOS}

Los huertos de palmeras se localizan, casi en su totalidad, en la margen izquierda del río Vinalopó ${ }^{(18)}$, pudiéndolos clasificar en varios grupos dependiendo de su ubicación. Así hay:

- huertos del casco urbano o que lo rodean formando una masa continua a partir de aquél;

- huertos aislados, más o menos próximos al bosque que rodea el núcleo urbano y que dan sensación de continuidad con los antes citados; y

-huertos totalmente aislados, repartidos a título individual por las diversas partidas del término.

Tanto los huertos urbanos como los adyacentes presentan tapias, entre 1,5 y 2 metros de altura, que forman caminos estrechos y han pervivido desde siglos atrás hasta nuestros días.

Todos los huertos suelen tener un nombre por el que se les identifica; sin embargo las escrituras de arrendamiento no siempre facilitan dicho nombre, limitándose, en ocasiones, a indicar su ubicación, partidor del que recibe el agua... Los huertos con nombre propio que hemos encontrado son los siguientes:

Huerto de Abajo
Huerto del Beneficio
Huerto del Ciprés
Huerto del Colomer
Huerto del Contador
Huerto de la Cruz
Huerto del Hondo
Huerto de los Murons
Huerto de las Peras

Huerto de la Rambla

Huerto del Real

Huerto de San Francisco

Huerto del Señor

Huerto del Sindico

Huerto de las Tahúllas

Huerto de las Tres

\section{CUADRO II}

REPARTO EN LA CESIÓN DE HUERTOS POR ESTAMENTOS

\begin{tabular}{|c|c|c|}
\hline GRUPO & N. ${ }^{\circ}$ DE CESIONES & PORCENTAJE \\
\hline 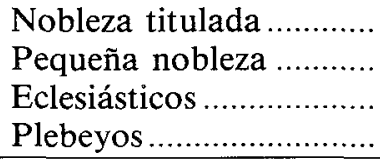 & $\begin{array}{r}3 \\
65 \\
19 \\
4 \\
\end{array}$ & $\begin{array}{r}3,29 \\
71,42 \\
20,87 \\
4,39 \\
\end{array}$ \\
\hline TOTAL & 91 & 100 \\
\hline
\end{tabular}

Fuente: A. M. E. Protocolos (elaboración propia) 
Como puede observarse (cuadro II), los huertos de palmeras pertenecían a la élite de la sociedad ilicitana ${ }^{(19)}$; no obstante, deben hacerse ciertas matizaciones ya que se constata la existencia de cuatro huertos cuya titularidad cambia de un arriendo a otro. Así:

- como titulares del huerto de San Francisco aparecen, por orden cronológico, el Marqués de Laconi (1717-1722), la Real Hacienda (1722-1727) y D. Juan Vaíllo de Llanos (desde 1727);

-igualmente, el huerto de Abajo lo arrienda de 1715 a 1726 el Marqués de Laconi, en tanto que a partir de este último año es D. Juan Vaíllo de Llanos quien lo cede en arrendamiento;

- también el huerto sito frente a la puerta pequeña de la parroquia del Salvador aparece en manos de la Orden de Montesa de 1717 a 1729, en tanto que a partir de esta última fecha es D. Isidoro Vaíllo de Llanos quien aparece arrendándolo;

-por último, el huerto de la Peras lo tiene desde 1718 a 1730 la Orden de Montesa, mientras desde este último año vuelve a su propietario, D. Isidoro Vaíllo de Llanos.

Las escrituras de arriendo no suelen ser muy explícitas en cuanto a la razón del cambio de titularidad de los huertos. Así, sólo cuando se trata de arrendamientos efectuados por D. Guillermo Olives, administrador de los bienes que posee en la villa de Elche la Orden de Montesa, se indica que esos huertos son los que tiene la citada Orden de D. Isidoro Vaíllo de Llanos, caballero de dicha Orden, aunque no se indica el motivo.

Los huertos de D. Juan Vaillo de Llanos forman parte, sin duda, de los bienes que, para el pago de 4.000 ducados de renta anual, tiene adjudicados el Marqués de Laconi de los bienes confiscados en este Reino ${ }^{(20)}$.

Señala Pradells Nadal ${ }^{(21)}$ cómo con las confiscaciones de propiedades en el bando austracista, a raíz de la Guerra de Sucesión, fueron numerosas y cómo «en el partido borbónico, el producto de las confiscaciones fue destinado a la restitución de las pérdidas de los que pudieron justificar haber mantenido su fidelidad así como premiar los servicios militares y administrativos prestados a la Corona». Sin embargo, «la promulgación del valimiento del $80 \%$, pronto reducido al $60 \%$, hizo disminuir la apetencia de hacerse cargo de propiedades que se presumía iban a ser reintegradas a firmar la paz - Tratado de Viena, 1725-. De hecho, a partir de 1726 las devoluciones fueron prácticamente generales en el caso de las propiedades de las clases nobiliarias».

Si como parece la familia Llanos era partidaria del archiduque ${ }^{(22)}$ y sufrió por ello confiscaciones tras finalizar la Guerra de Sucesión ${ }^{(23)}$, puede que también el aprovechamiento de los bienes de $\mathrm{D}$. Isidoro Vaíllo de Llanos por parte de la Orden de Montesa responda a este motivo. Con ello los porcentajes expresados arriba sufrirían ligeras variaciones, reduciéndose la nobleza titulada y el estamento eclesiástico para subir la pequeña nobleza. No obstante, y hecha esta salvedad, como aunque no tengan la propiedad real sí tienen la efectiva durante 
ese período, no caben modificaciones ya que la renta del arrendamiento va a sus manos como si de propietarios reales se tratara.

En cuanto a los arrendatarios señalar como rasgo distintivo el que muchos de ellos aparecen, de forma continuada, detentando el dominio útil de un mismo huerto a lo largo de todo el período, renovando, cada vez que se cumple el tiempo, el arrendamiento.

La duración del contrato suele oscilar entre los cuatro y ocho años, alcanzando el mayor porcentaje los arriendos por seis años (39'56\%).

Estos arriendos suelen comenzar mayoritariamente por San Juan (45'05\%), seguido de Navidad (19'78\%); se trata de dos fechas que marcan el calendario agrícola y que aparecen equidistantes entre sí. Con porcentajes algo más bajos se presentan otras fechas como San Miguel ( $\left.7^{\prime} 69 \%\right)$, primero de mes (12'08\%) y otras que pueden coincidir o no con la fecha de formalización de la escritura $\left(15^{\prime} 37 \%\right)$.

El precio que se paga anualmente por el arrendamiento de cada uno de los huertos varía en función de la cantidad de tierra que incluya, del agua de riego con que cuente, estado general del huerto, etc. La estimación del valor del arriendo no se puede hacer en base a la extensión ya que en las escrituras ésta no aparece; es por ello que para observar el comportamiento de los huertos, en cuanto a la renta se refiere, los hemos agrupado según el precio pagado por ellos anualmente. De esta manera puede observarse el número de huertos con renta más o menos elevada en el período 1715-1730.

\section{CUADRO III}

\section{RENTA DE HUERTOS (VALOR ANUAL)}

\begin{tabular}{|c|c|c|}
\hline PRECIO & N. ${ }^{\circ}$ DE HUERTOS & PORCENTAJE \\
\hline Hasta 30 libras ............. & 3 & 3,29 \\
De 31 a 60 libras......... & 28 & 30,76 \\
De 61 a 90 libras......... & 16 & 17,58 \\
De 91 a 120 libras ........ & 20 & 21,97 \\
De 121 a 150 libras ....... & 14 & 15,38 \\
De 151 a 180 libras ...... & 3 & 3,29 \\
De 181 a 200 libras ...... & 4 & 4,39 \\
Más de 200 libras......... & 3 & 3,29 \\
\hline TOTAL .................. & 91 & 100 \\
\hline
\end{tabular}

Fuente: A. M. E. Protocolos (elaboración propia)

Del cuadro III cabe destacar el predominio de huertos en los grupos de 31 a 60 libras y de 91 a 120; así como aquellos con rentas más bajas (inferiores a 
30 lbs.) cual son los huertos del Convento de la Merced, el del Hondo y el de la ermita de San Antón; entre las más altas (por encima de las 200 lbs.) figuran el huerto de los Murons y el que los Santacilia tienen en la huerta de la villa, bajo riego de Alcana.

La forma de pago que se establece mayoritariamente es en dos plazos $(62 ' 63 \%)$, siendo éstos casi siempre por Navidad y San Juan, aunque hay otras veces en que se produce en Navidad y agosto, o bien por San Miguel y Navidad. Le sigue en importancia el pago por tercias $\left(26^{\prime} 37 \%\right)$, esto es, tres pagas anuales de cuatro en cuatro meses, las cuales pueden ser anticipadas o fenecidas. Otras veces se indica que se abonará todo el precio de una vez al cumplirse el año $\left(5^{\circ} 49 \%\right)$, lo que suele coicidir en la mayoría de los casos con San Juan. Una última modalidad regula el pago de tres en tres meses (3'29\%).

Cuando el propietario reside fuera de Elche, en la mayoría de los casos establece que las pagas deberán entregársele en la ciudad en que vive ${ }^{(24)}$.

Entre las condiciones reguladas en los arriendos de huertos figuran:

a) El mantenimiento de la infraestructura del huerto y vivienda, con especial atención a la conservación del cercado - reparación de portillos-o a la creación del mismo en los huertos que no dispusieran de él ${ }^{(25)}$.

En los huertos que disponen de balsa se indica que al acabar el arrendamiento deberá encontrarse limpia, debiendo llevar los arrendatarios el cieno o lodo que de ella se sacase a la rambla.

Respecto a la vivienda algunos contratos son bastante descriptivos, perfilando una semblanza de la misma (número de puertas, deficiencias de la casa, estado de las paredes...) y fijando las obras que deberán hacer en ella los arrendatarios, ya sea con el fin de repararla o para una posible ampliación.

Unas últimas consideraciones, que enlazan con el siguiente subapartado, son las referentes a la limpieza del huerto. Así, se indica que por haber recibido los arrendatarios las tierras y las tiras limpias de palmas, las palmeras escamondadas y mondadas las acequias, deberán dejarlo de igual manera cuando se vayan.

b) Cultivo de palmeras. Muchas y variadas son las obligaciones que contraen los arrendatarios de huertos, entre ellas: plantar y criar un determinado número de palmeras cada año ${ }^{(26)}$; quitar las malas hierbas del huerto; cortas las palmas viejas - escamondar - , amontonándolas, una vez cortadas, fuera de las tiras para que no impidan el tránsito, o bien quemarlas; no atar («encapuruchar») ninguna palmera hembra, sino sólo los machos - y en este caso cortarlas ese mismo año, ya que no podrán estar atadas de un año para otro-; abonar con estiércol el huerto; regar cuantas veces sea posible; quitar retoños si no van a utilizarse para el trasplante; recogida de fruto, etc.

c) Hay una serie de cultivos que podían aparecer asociados a las palmeras, ya que éstas, distribuidas en filas paralelas a lo largo de los canales de riego, servían de linderos a los bancales, los cuales se aprovechaban en cereales y hortalizas, siendo lo más frecuente el alfalfar.

El cultivo de la alfalfa era muy importante en el Elche de principios del XVIII 
como perfilan los contratos de arrendamiento; así, en la mayoría se estipula que deberán dejarse mejoras en alfalfa por una determinada cantidad —en metálico o en plantados-. Si excediese de dicha cantidad el propietario del huerto abonaría la diferencia, y si fuera menor debería pagarlo el arrendatario.

Además de los cultivos ya señalados, algunos huertos comparten el aprovechamiento de las tierras con perales y granados, piso arbóreo intermedio entre las palmeras y los cultivos hortícolas y herbáceos.

d) Como ya se señaló en el apartado general de arrendamientos rústicos, muchos propietarios exigen a sus arrendatarios la entrega de cierta cantidad de frutos o aves. Esta cantidad solicitada es mayor en el caso de los arrendamientos de huertos, así el número de gallinas a entregar oscila entre 2 y 12 y la cantidad de dátiles entre 1 y 10 arrobas.

Las fechas en que solían dársele estos regalos al propietario dependen siempre de lo que éste determine. Así, mientras en algunos casos indica que deberían entregársele por Navidad o Santo Tomás, en otros prefiere fraccionarlos, exigiendo entonces la mitad por San Juan y la otra mitad por Navidad (caso de las aves). Para los frutos se estipula que deberán entregárse cuando lo pida el dueño, y de no hacerlo así éste podrá comprarlos a costa del arrendatario.

Otro tipo de prestaciones consiste en la entrega de determinadas cantidades de peras -1 ó 3 arrobas - o granadas -200 piezas, la mitad dulces y la otra mitad agridulces.

Algunos arrendadores, en vez de exigir una determinada cantidad de dátiles, se reservan determinadas palmeras dentro del huerto para abastecerse con sus dátiles; tal es el caso de D. Máximo Miralles de Imperial que se reserva la palmera llamada «del amo», D. Juan Vaíllo de Llanos «la Pasquala», etc.

e) Otras disposiciones que figuran en numerosos contratos hacen referencia a la posibilidad de subarrendar el huerto; presentación de fianzas; reservas, por parte del dueño, de ciertas tierras o la parte alta de la vivienda...

\section{CONCLUSIONES}

El análisis de las escrituras de arrendamientos rústicos ha permitido extraer conclusiones sobre la forma de cultivo de diferentes productos hortofrutícolas, así como sobre la presión, mayor o menor, que los propietarios ejercían sobre los arrendatarios. Respecto a este último punto cabe destacar que aunque de forma general no se constata una excesiva presión de los arrendadores sobre quienes toman en usufructo sus tierras, sí existen bastantes casos en los que se regula de antemano las numerosas obligaciones que deberán cumplir los arrendatarios; éstas se hacen presentes fundamentalmente en tres casos:

- arrendamiento de haciendas con múltiples aprovechamientos (viñas, olivares, frutales...),

-arrendamientos de huertos de palmeras, y

-aparcería. 
En cambio, en arriendos de parcelas de menor tamaño o cuyo único aprovechamiento es el olivar o cereal, los arrendatarios mantienen una mayor libertad de acción, debiendo someterse únicamente a las normas que les obligan a cultivar las tierras según costumbre de buen labrador.

Al margen del mayor o menor número de exigencias, existe la posibilidad de que éstas sean más o menos duras. Así, el clero de la iglesia de Santa María muestra una actitud bastante impositiva y un tanto al margen del resto de arrendadores, de tal manera que en todos los contratos que establece corre por cuenta del arrendatario el satisfacer los gastos de corredurías y escrituras, así como dar copia franca de la misma al otorgante. También el pacto agrícola referido a la poda o escamonda reviste particular dureza si lo comparamos con las condiciones que respecto al mismo establecen otros propietarios ${ }^{(27)}$.

Teniendo en cuenta que las tierras arrendadas por el clero de Santa María están plantadas de olivos y éste es un cultivo que no suele estar muy regulado, cabe señalar como bastante exigente a este sector del clero ilicitano, en tanto que las tierras cedidas por la parroquia de San Juan lo son si tantos condicionamientos y dejando mayor iniciativa a los arrendatarios.

Otro sector bastante exigente es el noble. Este estamento controla más del $48 \%$ de las tierras cedidas en arrendamiento, particularmente los huertos de palmeras y haciendas en las que no aparece determinada la extensión. En este grupo destacan los apellidos Perpiñán, Malla, Ruiz, Ortiz... procedentes de viejos linajes, catalanes y aragoneses, asentados en Elche desde el siglo XIII.

Por último, cerca del $30 \%$ de las tierras arrendadas pertenecen al estamento plebeyo. Estos individuos al ceder sus tierras no ponen muchos condicionamientos a quienes van a pasar a usufructuarlas, sino que por el contrario se conforman con un cuidado «según costumbre». 


\section{NOTAS}

(1) EIRAS ROEL, A.: «La Metodología de la investigación histórica sobre documentación notarial: para un estado de la cuestión. Introducción general», en Actas del II Coloquio de Metología Histórica Aplicada. La Documentación Notarial y la Historia, I. Santiago de Compostela, 1982. pp. 13-30.

(2) El presente artículo resume, en parte, las conclusiones a que llegamos en la Memoria de Licenciatura Estudio sobre el arrendamiento ilicitano en el siglo XVIII (1715-1730), facultad de Filosofía y Letras, Universidad de Alicante, 1986, dirigida por el Dr. D. Enrique Giménez López.

(3) Los pactos que regulan la actuación del arrendatario en estas tierras -labores, cuidados...son más numerosos e impositivos que en el arriendo de tierras dedicados a cualquier otro cultivo.

(4) Dentro de la pequeña nobleza han sido agrupados todos los individuos que aparecen intitulados con el término «don», aunque somos conscientes que durante el XVIII la utilización del «don» se extiende a profesionales liberales, comerciantes mayoristas, y en general, a personas socialmente consideradas.

(5) Los porcentajes respectivos están alrededor del $4 \%$, cifrándose, en concreto, en 3'85\% para los arrendatarios del estamento eclesiástico y 4 '3\% para los del noble.

(6) Vid. GIMÉNEZ LÓPEZ, E.: Alicante en el siglo XVIII. Economía de una ciudad portuaria en el Antiguo Régimen. Valencia, 1981, p. 129.

(7) También lo constata así GOERLICH PESET, J. M.: «Revolución liberal y arrendamientos rústicos en la práctica notarial valenciana", en Estudios dedicados a JUAN PESET ALEIXANDRE, Universidad de Valencia, 1982, pp. 199-200.

(8) Sobre la aparcería en el campo de EIche vid. Mi artículo «El arrendamiento ilicitano en el siglo XVIII (1715-1730)", en prensa.

(9) En estas haciendas de la huerta oriolana el total a pagar está compuesto por determinadas cantidades de frutos (trigo, garbanzos, lino), así como por cierto número de animales (lechones, gallinas). Además, suele tratarse de haciendas de gran extensión -más de 300 tahúllas.

(10) A. M. E. Protocolos, Sig. 718, Carlos Gracia, 1719-IX-21.

(I1) GOERLICH PESET, J. M.: Op. cit. pp. 204-205.

(12) Vertiente: declive por donde corre el agua cuando llueve y que suele desembocar en un algibe o bancal.

(13) Un reparto interesante, entre propietario y arrendatario, de las labores de mejora puede verse en A. M. E. Protocolos, Sig. 511, Cayetano Aznar, 1728-VII-26.

(14) RUIZ TORRES, P.: «Fuerzas productivas y producción agraria en el País Valenciano: crecimiento y crisis en el campo de Elche (1730-1850)", en Estudis 7 (1978), p. 89.

(15) En algunas partidas no se halla localizado ningún tipo de cultivo; ello se debe a que no ha aparecido ninguna cesión de tierras en esa partida en las escrituras consultadas.

(16) Para ampliar la información sobre el reparto de cultivos por partidas en el término ilicitano vid. GONZÁL VEZ PÉREZ, V.: El Bajo Vinalopó. Geografía Agraria. Valencia, 1977, pp. 98-104.

(17) CAVANILLES, A. J.: Observaciones sobre la Historia Natural, Geografía, Agricultura, Población y frutos del Reyno de Valencia. Madrid, 1795-97. Vol. II, p. 270.

(18) Se trata de las mejores tierras y con mayor y más fácil riego.

(19) Si de los datos presentes en el cuadro I eliminamos a los propietarios de huertos -que inflan los sectores más prepotentes de aquél- quedarían unos porcentajes de $41^{\prime} 7 \%$ para la nobleza, $23{ }^{\prime} 4 \%$ para el estamento eclesiástico y 34 ' $8 \%$ para los plebeyos. 
(20) A. M. E. Protocolos, Sig. 479, Felix Alcalá, 1718-XI-26.

(21) PRADELLS NADAL, J.: Del foralismo al centralismo. Alicante 1700-1725. Alicante, 1984, p. 234.

(22) En A. H. N. Consejos Suprimidos. Lib. 2496, fols. 186-189, 11-V-1728, se encuentra la copia de la Real Cédula por la que el Rey (Felipe V), en virtud de lo estipulado por la paz de Viena, accede a que subsista a favor de D. Juan Vaillo de Llanos y Ferrer el título de Conde de Torrellano que le concedió el emperador Carlos VI por Real despacho de 30 de mayo de 1716; lo que constituye suficiente prueba de la fidelidad al archiduque Carlos durante la guerra, por parte de D. Juan Vaillo de Llanos.

(23) Aparecen miembros de esta familia en las relaciones que, sobre bienes confiscados en Alicante presenta PRADELLS NADAL, J.: Op. cit. pp. 197, 199, 200, 204, 255, 266, 273.

(24) Idéntica condición figura en los arrendamientos de tierras dedicadas a cualquier otro cultivo.

(25) Las paredes de la cerca se harán con piedra y lodo.

(26) Sobre los distintos procedimientos de reproducción: por semilla, retoños, esquejes, vid. MUÑOZ PALAO, F. M.: La palmera datilera. Murcia, 1929, pp. 51-65; también AGULLÓ VELASCO, M. y GALIANA FERRÁNDEZ, C.: La palmera datilera. Cultivo y aprovechamiento. Alicante, 1983. pp. 101-109.

(27) Mientras el clero de Santa María indica que cuando haya de efectuarse la escamonda designará a un experto para que dirija las labores de poda - su jornal correrá por cuenta del arrendatario-, el resto de propietarios deja en manos del arrendatario dicha labor o bien manda a alguien para que supervise la manera de llevarlo a cabo, pero sin que el pago de este último corra a cargo de aquél. Así, con el sistema empleado por el clero de los arrendatarios invertían doble $n .^{\circ}$ de jornales - uno por ejecución y otro por supervisión. 